\title{
Aerodynamic Optimization Design of a Multistage Centrifugal Steam Turbine and Its Off-Design Performance Analysis
}

\author{
Hui $\mathrm{Li}^{1,2}$ and Dian-Gui Huang ${ }^{1,2}$ \\ ${ }^{1}$ School of Energy and Power Engineering, University of Shanghai for Science and Technology, \\ Shanghai 200093, China \\ ${ }^{2}$ Shanghai Key Laboratory of Power Energy in Multiphase Flow and Heat Transfer, Shanghai 200093, China \\ Correspondence should be addressed to Dian-Gui Huang; dghuang@usst.edu.cn
}

Received 8 April 2017; Revised 28 June 2017; Accepted 7 August 2017; Published 27 September 2017

Academic Editor: Ryoichi Samuel Amano

\begin{abstract}
Copyright (C) 2017 Hui Li and Dian-Gui Huang. This is an open access article distributed under the Creative Commons Attribution License, which permits unrestricted use, distribution, and reproduction in any medium, provided the original work is properly cited.
\end{abstract}

\begin{abstract}
Centrifugal turbine which has less land occupation, simple structure, and high aerodynamic efficiency is suitable to be used as small to medium size steam turbines or waste heat recovery plant. In this paper, one-dimensional design of a multistage centrifugal steam turbine was performed by using in-house one-dimensional aerodynamic design program. In addition, three-dimensional numerical simulation was also performed in order to analyze design and off-design aerodynamic performance of the proposed centrifugal steam turbine. The results exhibit reasonable flow field and smooth streamline; the aerodynamic performance of the designed turbine meets our initial expectations. These results indicate that the one-dimensional aerodynamic design program is reliable and effective. The off-design aerodynamic performance of centrifugal steam turbine was analyzed, and the results show that the mass flow increases with the decrease of the pressure ratio at a constant speed, until the critical mass flow is reached. The efficiency curve with the pressure ratio has an optimum efficiency point. And the pressure ratio of the optimum efficiency agrees well with that of the one-dimensional design. The shaft power decreases as the pressure ratio increases at a constant speed. Overall, the centrifugal turbine has a wide range and good off-design aerodynamic performance.
\end{abstract}

\section{Introduction}

With the continuous reduction of fossil energy and the enhancement of people's environment awareness, there has been increasing attention to the high efficiency utilization of energy, where the turbine is energy conversion component; if the turbine is improved effectively, it can help to improve the efficiency utilization of energy.

Centrifugal turbine is a new type of turbine engine which has many advantages. In the centrifugal turbine, the gas flows outward the center and the channel area of the flow path increase naturally as the fluid volume flow increases, during the expansion process. That meets the principle of aerodynamic and geometric matching. In addition, centrifugal turbine can be used to achieve multistage design [1] more easily than centripetal turbine. Thus it can avoid the limitation of supersonic flow. This is more useful for design conditions, especially for off-design performance conditions.
For turbine as the key component, many scholars in this area have done some relevant researches, but there is not much research on centrifugal turbine. Domestically, mainly Jing and Peng had studied the pneumatic analysis of a rocket centrifugal turbine prototype starter and designed the modification turbine [2]; Yin-Ge et al. [3] and Xin et al. [4, 5] had researched the single-stage centrifugal turbine design and its off-design performance. Abroad, the preliminary hydrodynamic design of a small centrifugal turbine for the ORC was studied by Casati and others of the Delft University of Technology. They introduced the optimization based on the intermediate streamline method for evaluating turbine design and performance [6-10].

In this paper, one-dimensional design method of centrifugal steam turbine is proposed by drawing on the conventional turbine [11]. And numerical simulation and optimization of multistage centrifugal turbine were studied 
by referring to the inlet and outlet thermal parameters of a small axial steam turbine.

\section{Aerodynamic Design of a Steam Centrifugal Turbine}

2.1. One-Dimensional Design Method. A one-dimensional design of centrifugal turbine has been developed, which is based on the one-dimensional design method of conventional turbine. The one-dimensional thermodynamic calculation program was developed by FORTRAN. The main design principles of centrifugal turbine one-dimensional design program are as follows:

(1) The expansion flow is assumed to be adiabatic, steady, and one-dimensional in the cascade channel.

(2) The properties of working fluids are obtained by calling Refpro 9.0, which is applicable to a variety of working fluid.

(3) In order to simplify the design of the blade, the blade is designed to be of straight and constant height.

(4) Stator and rotor velocity coefficients $\varphi$ and $\psi$ are based on previous experience [12].

(5) Each stage of the rotor absolute flow angle is 90 degrees.

(6) The program is mainly composed of continuity and energy equations to achieve one-dimensional design.

Figure 1 presents the design process of the centrifugal onedimensional aerodynamic program. The thermodynamic parameters of the centrifugal turbine, inlet stagnation temperature $T_{0}^{*}$, inlet stagnation pressure $P_{0}^{*}$, outlet pressure $P_{N}$, mass flow rate $G$, and rotation speed $n$, are based on original conventional turbine. The other parameters, impeller diameter ratio $b$ (the influence of diameter ratio on the centrifugal turbine wheel efficiency is referred to in [3]; the optimum wheel efficiency calculated at the optimum degree of reaction and speed ratio increases as the diameter ratio decreases; $\left.b_{N}=D_{N \text {,out }} / D_{N \text {,in }}\right)$, each stage outlet flow angle of stator $\alpha_{1}$, the radial gap $\delta\left(\delta=R_{r \text {,in }}-R_{s, \text { out }}\right.$ or $\delta=R_{s, \text { in }}-R_{r \text {, out }}$, because the passage area along the flow path remains constant in axial flow turbine or the flow area reduces in radial flow turbine, so the radial gap can be large in traditional turbine, while, in centrifugal turbine, the flow area increases with the working fluid expansion. If the radial gap is too large, it will make the working fluid compressive in the gap, which is bad for turbine working. So the radial gap for centrifugal turbine should be small.), and stage number $N$, are previously estimated. Iterative and screening methods are used to search the maximum wheel efficiency of the centrifugal turbine.

Figure 2 shows the overall stages $H$-S diagram. The superscript $*$ represents the stagnant state. The second numbers of subscript are as follows: 1 represents the stator and 2 represents rotor. Taking the first stage as an example, the introduction of design process is as follows:

(1) In the stator, the steam expands from state 0 to state 1 . Lines $0-1$ represent the actual expansion and lines $0-1 s$ is the ideal expansion. In this process, the pressure energies are transferred to kinetic energies. Then the thermal parameters, velocity and geometry parameters can be calculated by using

isentropic expansion: $s_{0}=s_{1,1 s}=f\left(P_{0}^{*}, T_{0}^{*}\right)$

$$
h_{1,1 s}=f\left(s_{1,1 s}, P_{1,1}\right)
$$

energy equation: $h_{0}^{*}=h_{1,1 s}+\frac{c_{1,1 s}^{2}}{2}=h_{1,1}+\frac{c_{1,1}^{2}}{2}$

$$
\begin{aligned}
c_{1,1} & =\varphi c_{1,1 s} \\
s_{1,1}, \rho_{1,1} & =f\left(h_{1,1}, P_{1,1}\right)
\end{aligned}
$$

continuity equation: $G=\rho_{0} c_{0} A_{0}=\rho_{1,1} c_{1,1} A_{1} \sin \alpha_{1}$

$$
\chi_{1}=\frac{u_{1,1}}{c_{1,1 s}}=\frac{\pi n D_{1,1 \mathrm{out}}}{60 c_{1,1 s}} .
$$

(2) Then, in the rotor, the steam continues to expand from state 1 to state 2 . Lines $1-2$ represent the actual expansion and lines $1-2 s$ is the ideal expansion. The fluid kinetic energies are transferred to mechanical energies, which make the turbine outputs shaft power. The thermal parameters and the velocity triangles can be calculated by using

$w_{1,1}=\sqrt{c_{1,1}^{2}+u_{1,1}^{2}-2 c_{1,1} u_{1,1} \cos \alpha_{1}}$

$\sin \beta_{1}=\frac{c_{1,1} \sin \alpha_{1}}{w_{1,1}}$

continuity equation: $\rho_{1,1} c_{1,1} A_{1} \sin \alpha_{1}$

$$
=\rho_{1,2} A_{2} \sin \alpha_{2} \sqrt{\psi^{2}\left(w_{1}^{2}+2 \Delta h_{2 s}+u_{1,2}^{2}-u_{1,1}^{2}\right)-u_{1,2}^{2}}
$$

energy equation: $h_{1,1}+\frac{w_{1,1}^{2}}{2}-\frac{u_{1,1}^{2}}{2}$

$$
=h_{1,2 s}+\frac{w_{1,2 s}^{2}}{2}-\frac{u_{1,2}^{2}}{2}
$$

$w_{1,2}=\psi w_{1,2 s}$

isentropic expansion: $s_{1,2 s}=s_{1,1}=f\left(P_{1,1}^{*}, T_{1,1}^{*}\right)$

$P_{1,2}=f\left(s_{1,2 s}, h_{1,2 s}\right)$

$s_{1,2}, \rho_{1,2}^{\prime}=f\left(P_{1,2}, h_{1,2}\right)$

$\alpha_{2}=90^{\circ}$,

$c_{1,2}=\sqrt{w_{1,2}^{2}-u_{1,2}^{2}}$

$\operatorname{tg} \beta_{2}=\frac{c_{1,2}}{u_{1,2}}$.

(3) The rotor actual outlet density $\rho_{1,2}^{\prime}$ is compared with estimated density $\rho_{1,2}$. If $\left|\rho_{1,2}^{\prime}-\rho_{1,2}\right|<\varepsilon(\varepsilon$ is 


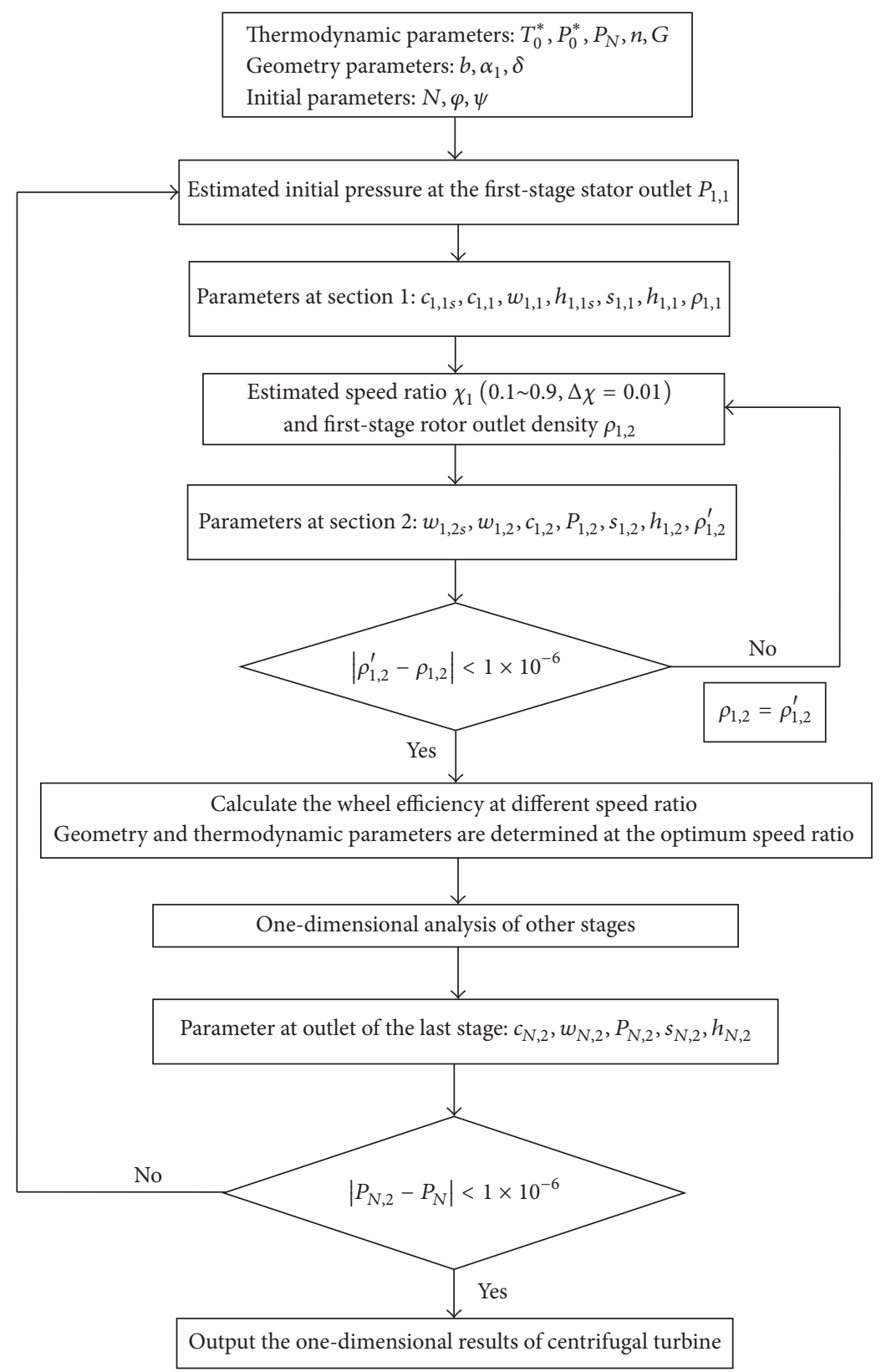

FIGURE 1: One-dimensional design process of centrifugal turbine.

a minimum), the assumption density $\rho_{1,2}$ is valid. Then the rotor outlet point is determined. If it is not satisfied, then reassume $\rho_{1,2}$ and repeat the above steps until the conditions are met.

(4) Similar to the axial flow turbine, the relevant adiabatic efficiency is given by (3), which is referred to in [13].

$$
\eta=\frac{h_{0}-h_{1,2}}{h_{0}-h_{1,2 s}^{\prime}} .
$$

The wheel efficiency is calculated at different speed ratio to select the optimum speed ratio and other corresponding parameters at maximum efficiency. Geometry and thermodynamic parameters are identified at the optimum speed ratio.
The above-mentioned steps are also adopted to design other stages.

2.2. One-Dimensional Design Results. The one-dimensional design program of the centrifugal turbine is used to design the multistage centrifugal turbine. The initial design thermal parameters are derived from a small axial turbine and summarized in Table 1.

Because there is no stage number information about the original axial turbine from the product information, the different stage number was tested to design the centrifugal turbine by using the one-dimensional design program. The results show that if the stage number is 1 and 2 , there is supersonic in the centrifugal turbine. As the stage number 


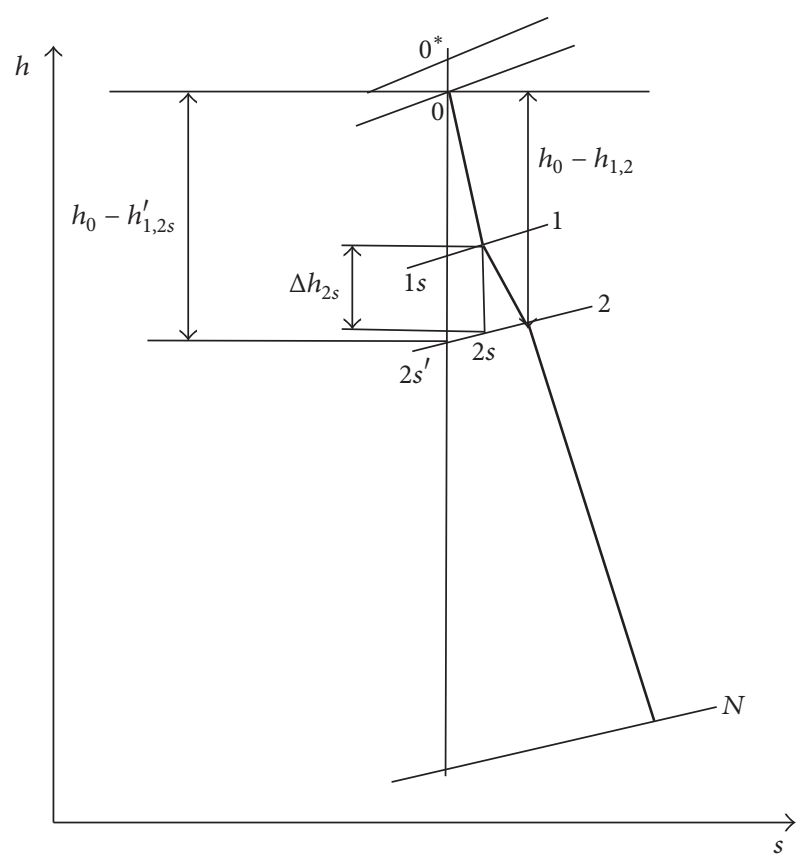

FIgURE 2: Turbine expansion process.

TABLE 1: The initial design parameters of the centrifugal turbine.

\begin{tabular}{lc}
\hline Total pressure $P_{0}(\mathrm{~Pa})$ & 1275000 \\
Total temperature $T_{0}(\mathrm{~K})$ & 613 \\
Back pressure $P_{N}(\mathrm{~Pa})$ & 294000 \\
Rotational speed $n(\mathrm{rpm})$ & 6500 \\
Mass flow $G(\mathrm{~kg} / \mathrm{s})$ & 16.7 \\
Rated power $W(\mathrm{~kW})$ & 750 \\
\hline
\end{tabular}

increased, there is no supersonic in the centrifugal turbine, but the size of the centrifugal turbine becomes more and more large. When the stage number is 3 , and the diameter ratio is 1.12, the centrifugal turbine is subsonic, and it can satisfy the enthalpy drop as well as high efficiency. So the centrifugal turbine is designed with three stages.

Then, the same blade height and the absolute airflow angle of each stage are 90 degrees as the criteria, impeller diameter ratio is estimated to be 1.12 for each stage, each stage outlet flow angle of stator is assumed to be 12 degrees, and radial clearance between stator and rotor is set to be $2 \mathrm{~mm}$. The optimal efficiency and reasonable structure are the objectives. The design parameters are calculated by using the above-mentioned one-dimensional calculation program, with iterative and screening methods. In this paper, the designed three-stage centrifugal turbine just meets the required enthalpy drop and has a very high wheel efficiency. The main aerodynamic parameters of each stage are shown in Table 2, and the main aerodynamic parameters of overall centrifugal turbine are shown in Table 3 . The geometry parameters are shown in Table 4 , and the speed triangle data is shown in Table 5. The speed triangle schematic diagram is shown as Figure 3.
1 st
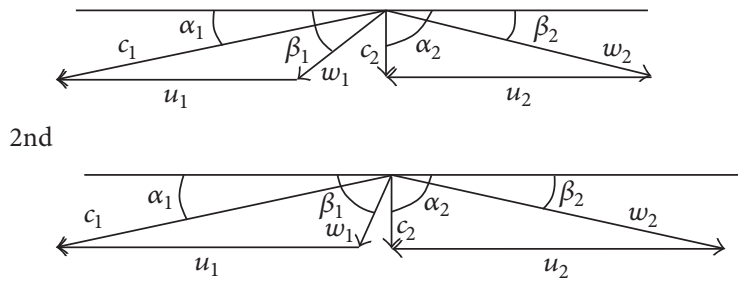

3rd

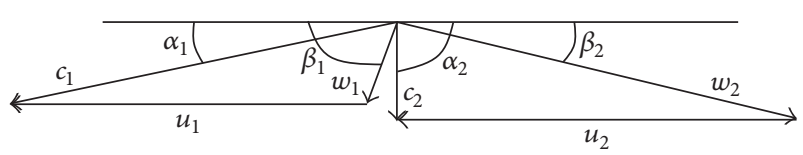

Figure 3: The speed triangle of the centrifugal turbine.

\section{Airfoil Design and Optimization}

The working fluid flows are outward the center in the centrifugal turbine. The passage area along the flow path increases naturally with the expansion of the working fluid, which makes the variety of specific volume matches the change of flow passage area. It can be seen that the centrifugal turbine is much superior to the conventional turbine from the structure. In the centrifugal turbine, the blade plane flow channel is expanding outward with the increase of the radius. It is obviously inappropriate to use the airfoil of conventional turbine at this time. So designing a suitable airfoil for centrifugal turbine is needed.

3.1. Parametric Expression of Airfoil. Angle and thickness design method is adopted to design airfoil, by using the inlet and outlet geometry angle, blade height, and leading and trailing edge diameters, which are based on one-dimensional design results in Tables 3 and 4. On the BladeGen platform, two-dimensional structure of the stator and rotor is identified. Stator and rotor of the first stage are an example, as shown in Figures 4(a) and 4(b). The blade surface includes four patches, namely, the leading edge and the trailing edge and the suction side and the pressure side. The mean camber line is controlled by cubic Bezier curve. The leading and trailing edges are both ellipse. Blade number is determined initially by referring to the relative pitch and expelling coefficient and the data is provided in [12]. The final numbers of stator and rotor for each stage are both 65 .

3.2. Blade Optimization for Three-Stage Centrifugal Steam Turbine. In the optimization process of blade, the blade number, the blade inlet and outlet geometry angles, and the leading and trailing edge thicknesses are the fixed parameters, and two control points of the tangent angle and two control points of the blade thickness are taken as the optimization parameters. Workbench is as the optimization software, and NLPQL algorithm is used as optimization method.

In the stator optimization process, the minimum loss coefficient is the object and stator back pressure is the constraint condition. Stators of three-stage centrifugal turbine 
TABLE 2: The main aerodynamic parameters of each stage.

\begin{tabular}{lccc}
\hline Stage number & 1 st & 2nd & 3rd \\
Speed ratio $X i$ & 0.69 & 0.86 & 0.87 \\
Reaction degree $\Omega$ & 0.322 & 0.453 & 0.468 \\
Flow coefficient $\varphi$ & 0.97 & 0.97 & 0.97 \\
Flow coefficient $\psi$ & 0.95 & 0.95 & 0.95 \\
Mach number of stator Ma & 0.55 & 0.58 & 0.76 \\
Shaft power $W(\mathrm{~kW})$ & 1205 & 1551 & 2436 \\
Wheel efficiency $\eta$ & $91.20 \%$ & $90.97 \%$ & $90.98 \%$ \\
\hline
\end{tabular}

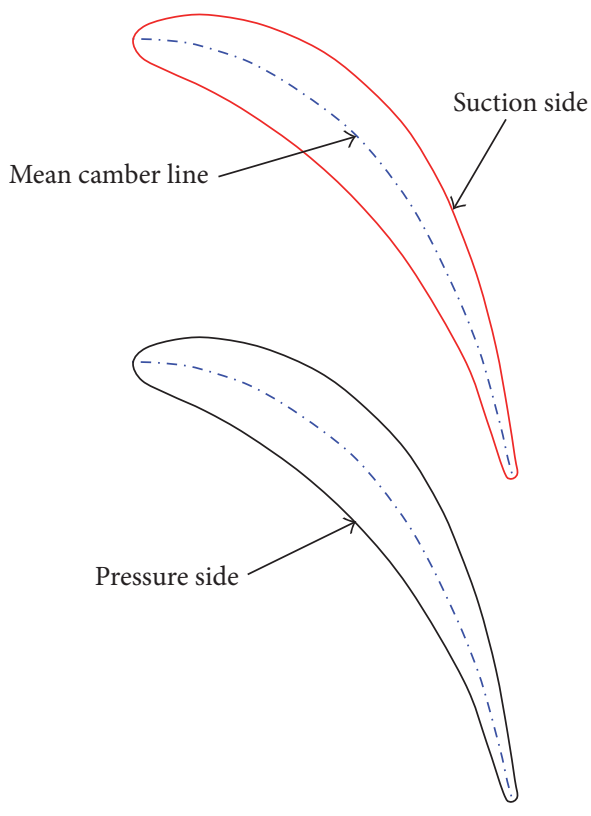

(a) Initial profile of the first-stage stator

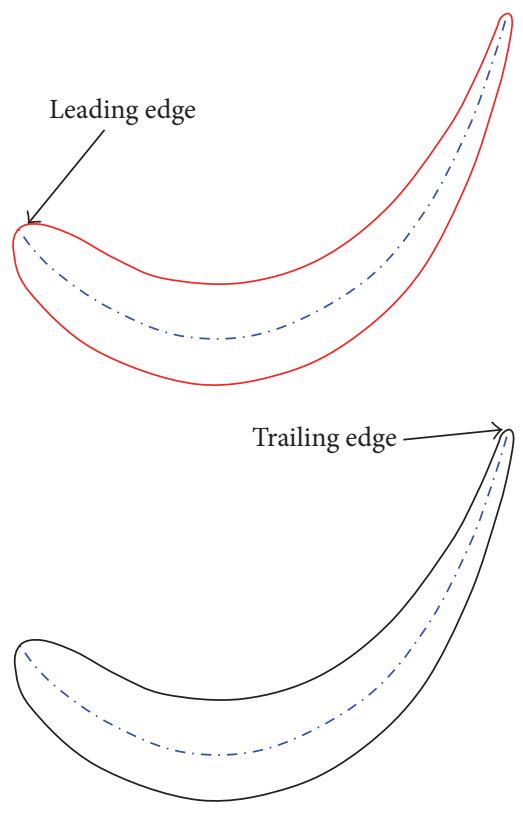

(b) Initial profile of the first-stage rotor

Figure 4

TABLE 3: The main aerodynamic parameters of overall centrifugal turbine.

\begin{tabular}{lc}
\hline Overall wheel efficiency $\eta$ & $90.50 \%$ \\
Overall shaft power $W(\mathrm{~kW})$ & 5192 \\
Mass flow $G(\mathrm{~kg} / \mathrm{s})$ & 16.7 \\
Back pressure $P_{N}(\mathrm{~Pa})$ & 294000 \\
\hline
\end{tabular}

are optimized, respectively. The optimization mathematical model of stator is expressed as

Object: Min (lossCoefficient)

$$
\begin{array}{ll}
\text { Constraint: } & P_{\mathrm{te}, 1} \leq P_{N, 1} \\
& =f\left(X_{\theta[1,2]}, Y_{\theta[1,2]}, X_{t[1,2]}, Y_{t[1,2]}\right) .
\end{array}
$$

The design variables $X_{\theta[1,2]}, Y_{\theta[1,2]}$, respectively, are the horizontal and vertical coordinates of control points of the tangent angle. $X_{t[1,2]}$ and $Y_{t[1,2]}$ are the horizontal and vertical coordinates of control points of the blade thickness. A total of eight variables are involved in optimization (the stator of the first stage is an example, as shown in Figure 5). $P_{\text {te, } 1}$ represents the pressure at the trailing edge of the stator, and $P_{N, 1}$ represents the stator back pressure of one-dimensional design ( $N$ represents stage number).

Then the rotor is added behind the optimized stator. The maximum shaft power is the object and rotor back pressure is the constraint condition. The optimization mathematical model of rotor is expressed as

$$
\begin{aligned}
\text { Object: } & \operatorname{Max} \text { (ShaftPower) } \\
\text { Constraint: } & P_{\mathrm{te}, 2} \leq P_{N, 2} \\
& =f\left(X_{\theta[1,2]}, Y_{\theta[1,2]}, X_{t[1,2]}, Y_{t[1,2]}\right) .
\end{aligned}
$$

The same as the stator, the design variables $X_{\theta[1,2]}$ and $Y_{\theta[1,2]}$ are the horizontal and vertical coordinate points for controlling the tangent angle of the rotor mean camber line, respectively. $X_{t[1,2]}$ and $Y_{t[1,2]}$ are the horizontal and vertical coordinate points for controlling the thickness of the blade. A total of eight variables are involved in optimization (the rotor of the first stage is an example, as shown in Figure 6). $P_{\text {te, } 2}$ represents the pressure at the trailing edge of the rotor, and 
TABLE 4: The main geometrical parameters of the centrifugal turbine.

\begin{tabular}{lccc}
\hline Stage number & 1 st & 2nd & 3rd \\
Stator inlet diameter $D_{s, \text { in }}(\mathrm{m})$ & 0.597 & 0.758 & 0.959 \\
Rotor outlet diameter $D_{r, \text { in }}(\mathrm{m})$ & 0.754 & 0.955 & 1.208 \\
Radial clearance $\delta_{N}(\mathrm{~m})$ & 0.002 & 0.002 & 0.002 \\
Blade height $H(\mathrm{~m})$ & 0.03 & 0.03 & 0.03 \\
Symmetrical cone angle $\gamma_{N}($ degree $)$ & 0 & 0 & 0 \\
Diameter ratio of stator $D_{s, \text { out }} / D_{s, \text { in }}$ & 1.12 & 1.12 & 1.12 \\
Diameter ratio of rotor $D_{r, \text { out }} / D_{r, \text { in }}$ & 1.12 & 1.12 \\
\hline
\end{tabular}

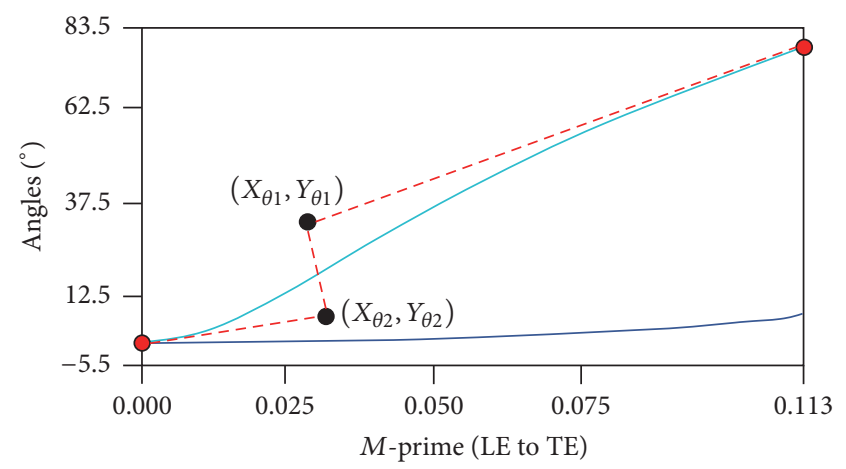

(a) Tangential angular distribution of medial camber line and control points selection of rotor blade

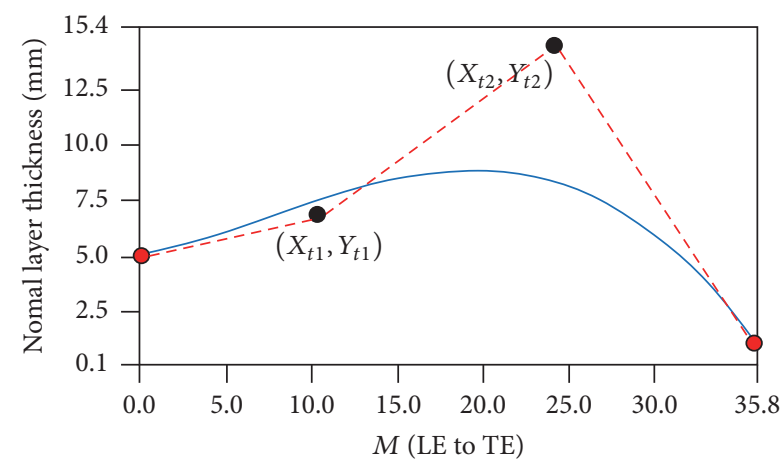

(b) The thickness distribution and control points selection of rotor blade

Figure 5

$P_{N, 2}$ represents the rotor back pressure of one-dimensional design.

The optimization strategy and process are shown in Figures 7 and 8, respectively.

Figure 8 shows the blade optimization process. All of those were simulated automatically on the workbench. Firstly, the value range of optimization parameters $\left(X_{\theta[1,2]}, Y_{\theta[1,2]}\right.$, $X_{t[1,2]}$, and $\left.Y_{t[1,2]}\right)$, constraint condition, and object are set artificially. Then, Design Exploration selects a set of data in the value range of optimization parameters, automatically. The blade geometry and parameterization are obtained by geometry software. After that, the blade mesh is generated by TurboGrid, and centrifugal turbine is simulated by CFX. Finally, if the results satisfy the constraint and object, the parameter values of blade control points are the optimization values. If not, the Design Exploration will select another set of data in the value range of optimization parameters, automatically. Then repeat the above steps until the conditions are met. Since the optimized stages deviate from the design condition, when they are calculated together, the leading and trailing edge thicknesses of stator and rotor are needed to be changed slightly for local adjustment, then the centrifugal turbine can obtain a better performance.

Since the SST model is used in turbomachinery, in most cases, it requires $Y^{+}$to be very small $\left(Y^{+}<2\right)$. So the layer mesh quality requirement of SST model is higher than $k$ epsilon model. If the SST uses the same mesh generated for $k$ epsilon, the layer mesh quality for SST is not good and cannot satisfy the requirement. The global size factors were changed to increase the mesh number, and the mesh quality was improved. So the grid number of SST is more than $k$-epsilon. It is about 8627,000 , while the grid number of $k$-epsilon model is 4010,000 . If the multistage centrifugal turbine simulation turbulence model was SST, a lot of computing memory will be needed; meanwhile a lot of calculating time will be cost. We found that the calculation results of SST and $k$-epsilon models are almost the same, as shown in Table 6, so there is no difference between SST model and $k$-epsilon model to simulate the multistage centrifugal turbine. In order to relax the demand on computer memory and to raise the efficiency when the computational grid number is very large, the $k$-epsilon model is used as the turbulence model to simulate the centrifugal turbine.

The optimized centrifugal turbine is simulated by CFX, based on Navier-Stokes equations. Stators and rotors use structured grid generated in TurboGrid, and the total grid number is about 4010,000; the blade global size factors of mesh are $1.2,1.2,1.25,1.25,1.25$, and 1.2 for each stator and rotor, respectively. The computational model mesh used for simulation is shown in Figure 9. The boundary conditions are inlet total pressure, total temperature, back pressure, and adiabatic wall. The turbine rotation speed is $6500 \mathrm{rpm}$. A no-slip boundary condition is applied at all the solid walls. The stator-rotor interface is Frozen Rotor. Separate periodic conditions are used for rotor and stator regions. $K$-epsilon is used as the turbulence model, and the fluid is Water Ideal Gas.

The optimal parameters of stator and rotor are almost consistent with one-dimensional aerodynamic design. The optimized stator and rotor of whole stages are both straight blades and the blade diagram is referred to in Figure 10. 


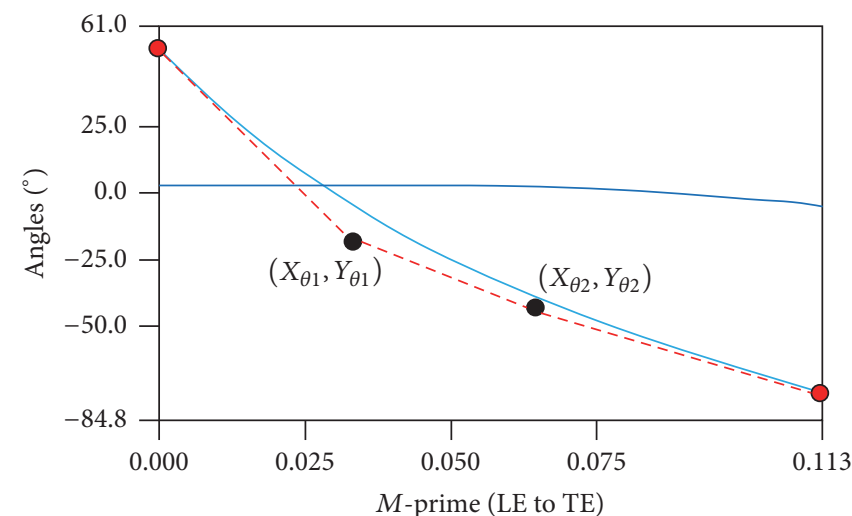

(a) Tangential angular distribution of medial camber line and control points selection of stator blade

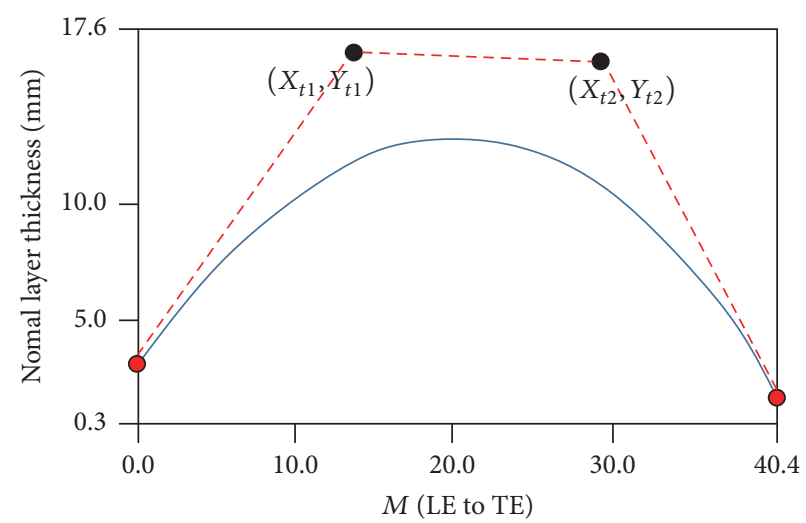

(b) The thickness distribution and control points selection of stator blade

Figure 6

TABle 5: The speed triangle data of the centrifugal turbine.

\begin{tabular}{lccc}
\hline Stage number & 1 st & 2nd & 3rd \\
$\alpha_{1}\left(^{\circ}\right)$ & 12 & 12 & 12 \\
$\beta_{1}\left({ }^{\circ}\right)$ & 37.93 & 64.47 & 68.44 \\
$C_{1}(\mathrm{~m} / \mathrm{s})$ & 322.1 & 328.7 & 408.1 \\
$W_{1}(\mathrm{~m} / \mathrm{s})$ & 108.9 & 75.74 & 91.22 \\
$U_{1}(\mathrm{~m} / \mathrm{s})$ & 229.1 & 290.3 & 367.0 \\
$\alpha_{2}\left({ }^{\circ}\right)$ & 90 & 90 & 90 \\
$\beta_{2}\left({ }^{\circ}\right)$ & 14.18 & 12.32 & 13.84 \\
$C_{2}(\mathrm{~m} / \mathrm{s})$ & 64.81 & 71.02 & 101.3 \\
$W_{2}(\mathrm{~m} / \mathrm{s})$ & 264.6 & 332.8 & 423.3 \\
$U_{2}(\mathrm{~m} / \mathrm{s})$ & 256.6 & 325.1 & 411.0 \\
\hline
\end{tabular}

TABLE 6: The contrast of SST and $k$-epsilon models.

\begin{tabular}{lccr}
\hline Variable & K-epsilon & SST & $\Delta$ \\
\hline Wheel efficiency $\eta$ & $93.29 \%$ & $93.01 \%$ & $0.29 \%$ \\
Shaft power $W(\mathrm{~kW})$ & 5387 & 5256.8 & $2.42 \%$ \\
Mass flow $G(\mathrm{~kg} / \mathrm{s})$ & 16.708 & 16.443 & $1.59 \%$ \\
Back pressure $P_{N}(\mathrm{~Pa})$ & 291170 & 293999 & $0.97 \%$ \\
\hline
\end{tabular}

\section{Results and Discussion}

4.1. Design Condition Aerodynamic Performance. The numerical simulation results of the optimized centrifugal turbine are basically consistent with the one-dimensional aerodynamic design, which shows that the one-dimensional design program is reliable and effective. The overall performance data of centrifugal turbine is shown in Table 7. Comparison of performance data at each stage is shown in Table 8. Seen from Table 8, the performance data has some deviations at each stage. This is because the optimized stages influence each other during the matching process. So it results in some deviations in the performance data. And these deviations are gradually accumulated in the process of fluid flow. As the stage increases, the deviations are more. But, from the overall performance data seen in Table 7 , the overall performance data is within $4 \%$ deviation. This is due to the fact that there are positive and negative deviations at each stage, which can offset each other. So the overall performance data of one-dimensional design and simulation results is not quite different. From the total shaft power and wheel efficiency, the simulation results of overall centrifugal turbine are better than one-dimensional design values. The threestage centrifugal turbine meets the design requirements and has good performance.

Figures 11-13 show the distribution of pressure, Mach number, and velocity streamline at the middle plane of the three-stage centrifugal turbine, respectively. From the diagrams, the pressure distribution is uniform; the main flow in the impeller is the pressure flow. The flow field in the cascade channel is reasonable, and the streamline is smooth and the aerodynamic performance is in line with the expectation. As 


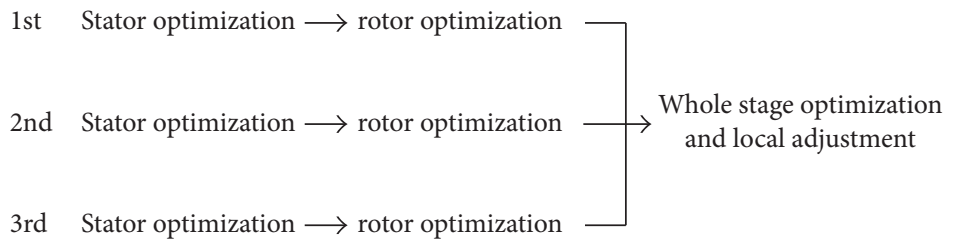

FIGURE 7: Optimization strategy.

TABLE 7: The contrast of design value and CFD value of the overall performance of the centrifugal turbine.

\begin{tabular}{lccr}
\hline Variable & Design value & Simulation value & \multicolumn{1}{c}{$\Delta$} \\
\hline Wheel efficiency $\eta$ & $90.50 \%$ & $93.29 \%$ & $+3.08 \%$ \\
Shaft power $W(\mathrm{~kW})$ & 5192 & 5387 & $+3.75 \%$ \\
Mass flow $G(\mathrm{~kg} / \mathrm{s})$ & 16.7 & 16.708 & $+0.05 \%$ \\
Back pressure $P_{N}(\mathrm{~Pa})$ & 294000 & 291170 & $-0.96 \%$ \\
\hline
\end{tabular}

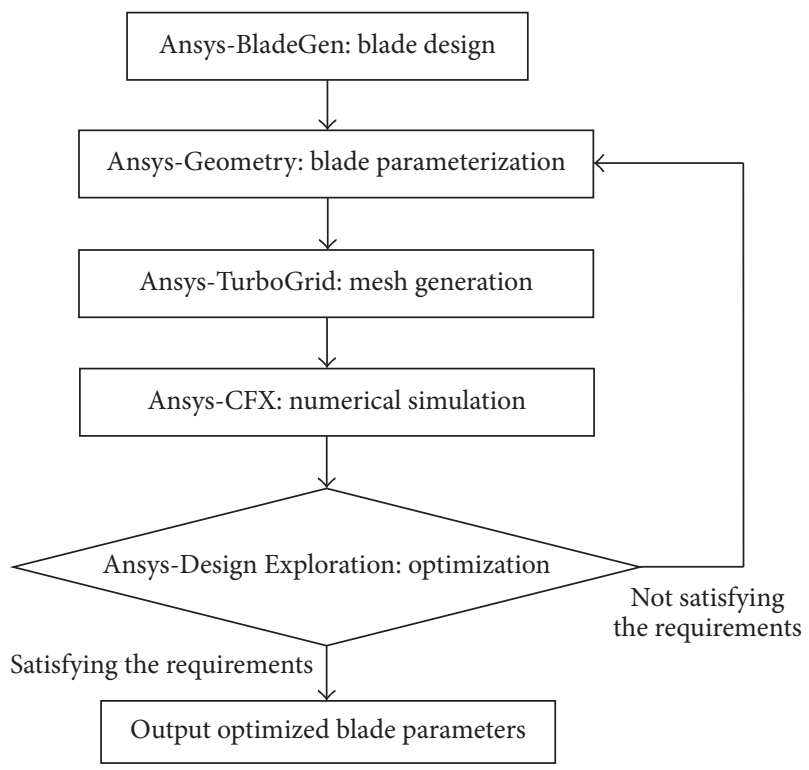

FIGURE 8: Optimization process.

can be seen from Table 8, the stator and rotor outflow angles of the first and second stage have deviation from the onedimensional design value. From the analysis of the flow field diagram, there is a flow separation in the small area near the trailing edge; the fluid expands at the chamfered part of the stator outlet and the gap between the rotor and stator, which results in deflection of the flow angle. The flow loss caused by the separation and the deviation of the inflow angle caused by the flow deflection are not yet considered in the one-dimensional design procedure. This is also the reason why the simulation results deviate from the one-dimensional design values.

4.2. Off-Design Condition Aerodynamic Performance. Figures 14,15 , and 16 show the relationship between mass flow $G$, efficiency $\eta$, and shaft power $W$ at different rotation speeds with variable pressure ratio $\pi=P_{N} / P_{0}^{*}$. The results indicate that as $\pi$ decreases, the mass flow increases until the critical flow is reached and then the mass flow remains constant, when the speed is constant. This is because the flow process appeared supersonic, and the flow reached its maximum. And the flow passage had the blocking phenomenon, but the turbine was still able to work. There is an optimal efficiency point on the efficiency with pressure ratio curve. At both sides of the optimal efficiency point, the efficiency decreases with the increase or decrease of $\pi$. This is due to the change of the back pressure, and the enthalpy drop is changed, the speed ratio is deviated from the optimum value, the flow angel is deflected, and the blade surface occurs the flow separation. Those lead to the flow loss increase and efficiency decrease. For shaft power, the power decreases as $\pi$ increases. Because of increase in back pressure, the enthalpy drop of the whole stage is reduced. Then the work capacity of working fluid is reduced. So the shaft power decreases with the increasing $\pi$. When the rotation speed changes, the optimum efficiency point moves in the direction of pressure ratio decreasing and the optimum efficiency value decreases with the increase of the rotation speed. But the efficiency trend with the pressure ratio is consistent at different speeds. For the mass flow, the flow characteristics at different rotation speeds are basically the same. It can be seen that the mass flow variation at different rotation speeds is the same and the change has little effect on mass flow. At different rotation speeds, the trends of shaft power curves are basically the same. But the curve of shaft power with the pressure ratio is steeper with the increase of rotation speed.

\section{Conclusions}

The three-stage centrifugal turbine is simulated by CFX with Water Ideal Gas as working fluid, drawing on the conventional turbine aerodynamic design method and offdesign condition performance research method. Conclusions are as follows.

The numerical simulation results of the whole stages are basically consistent with the one-dimensional design results, and the aerodynamic performance meets the expected requirements, which indicates the reliability and effectiveness 


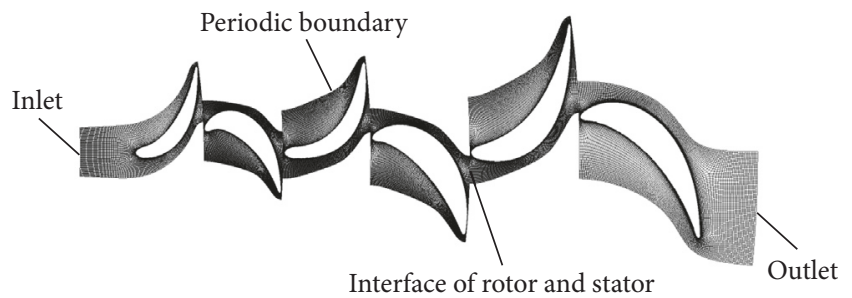

(a) Computational domain for the simulation of stages

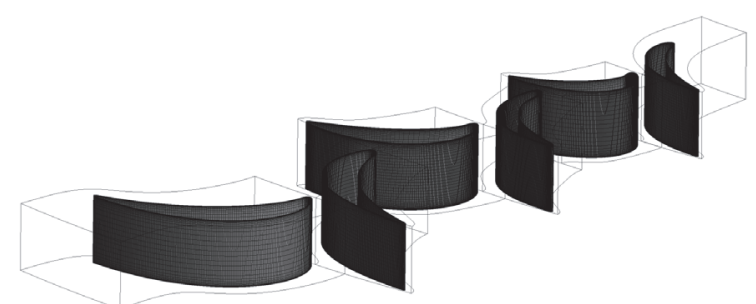

(b) Mesh distribution along the height and tangential direction of blade

Figure 9

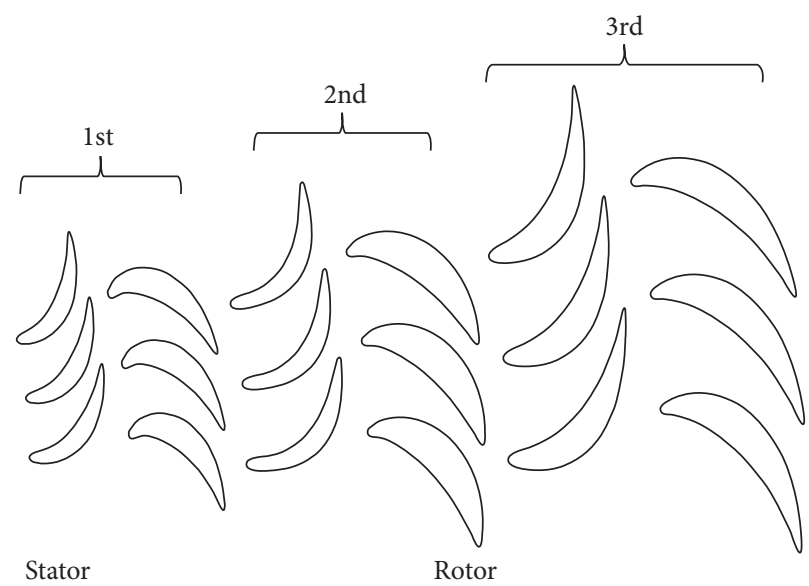

(a) Optimized stators and rotors

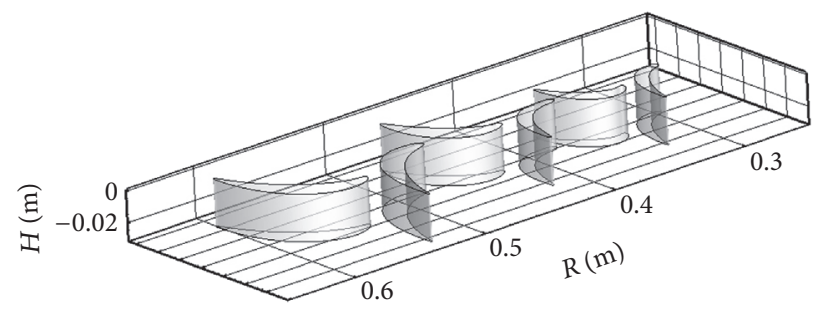

(b) $3 \mathrm{D}$ model of stator and rotor blades

FIGURE 10

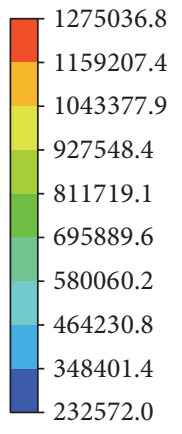

(Pa)

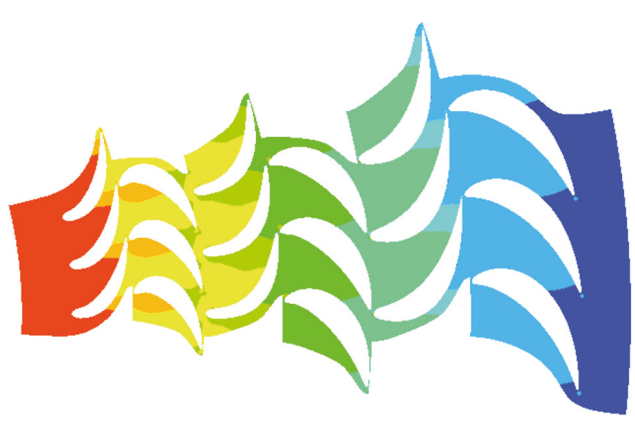

FIGURE 11: Static pressure distribution.

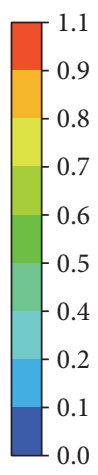

0.0

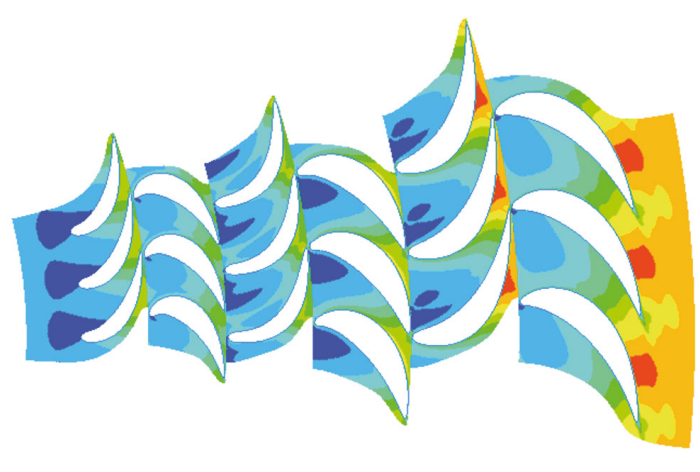

Figure 12: Mach number distribution. of the centrifugal turbine design. Because each stage of centrifugal turbine is optimized, the simulated overall efficiency is $3.08 \%$ higher than the one-dimensional design efficiency and the shaft power is $3.75 \%$ more than the one-dimensional design shaft power. At the design condition, the streamline of three-stage centrifugal steam turbine is smooth at cascade flow channel, the pressure distribution is uniform, and the flow field is reasonable.

At the off-design condition, when the speed is constant, the pressure ratio $\pi$ reaches the critical ratio and the mass flow reaches the maximum. If $\pi$ continues to decrease, the maximum flow value remains the same, and the flow passage has the blocking phenomenon. But the turbine is still able to work. At the same $\pi$, the speed decreases; then the mass flow increases; but the impact is quite small.

At a constant speed, the efficiency is highest at optimum pressure ratio $\pi$. The pressure ratio of the optimum efficiency agrees well with that of the one-dimensional design. When the speed decreases, the efficiency curve moves to the place where $\pi$ increases, and the corresponding maximum efficiency increases.

The shaft power curve trend with pressure ratio is similar at different rotation speeds. But as the rotation speed 
TABLE 8: The contrast of design value and CFD value of each stage performance of the centrifugal turbine.

\begin{tabular}{|c|c|c|c|c|c|c|c|c|c|}
\hline \multirow{3}{*}{ Variable } & \multicolumn{9}{|c|}{ Stage number } \\
\hline & \multicolumn{3}{|c|}{1 st } & \multicolumn{3}{|c|}{ 2nd } & \multicolumn{3}{|c|}{$3 \mathrm{rd}$} \\
\hline & Design value & Simulation value & $\Delta(\%)$ & Design value & Simulation value & $\Delta(\%)$ & Design value & Simulation value & $\Delta(\%)$ \\
\hline $\mathrm{Ma}$ & 0.55 & 0.55 & 0 & 0.58 & 0.52 & -10.34 & 0.76 & 0.82 & +7.89 \\
\hline$\Omega$ & 0.32 & 0.30 & -6.25 & 0.45 & 0.51 & +13.33 & 0.47 & 0.42 & -10.64 \\
\hline$\chi$ & 0.69 & 0.63 & -8.69 & 0.86 & 0.73 & -15.12 & 0.87 & 0.67 & -22.99 \\
\hline$W(\mathrm{~kW})$ & 1205 & 1231 & +2.16 & 1551 & 1384 & -10.77 & 2436 & 2771 & +13.75 \\
\hline$\eta(\%)$ & 91.20 & 93.34 & +2.35 & 90.97 & 87.36 & -3.97 & 90.98 & 89.59 & -1.53 \\
\hline$\alpha_{1}\left({ }^{\circ}\right)$ & 12.0 & 12.3 & +2.5 & 12.0 & 14.2 & +18.3 & 12.0 & 12.0 & 0 \\
\hline$\alpha_{2}\left({ }^{\circ}\right)$ & 90.0 & 78.9 & -12.3 & 90.0 & 80.3 & -10.8 & 90.0 & 90.0 & 0 \\
\hline
\end{tabular}

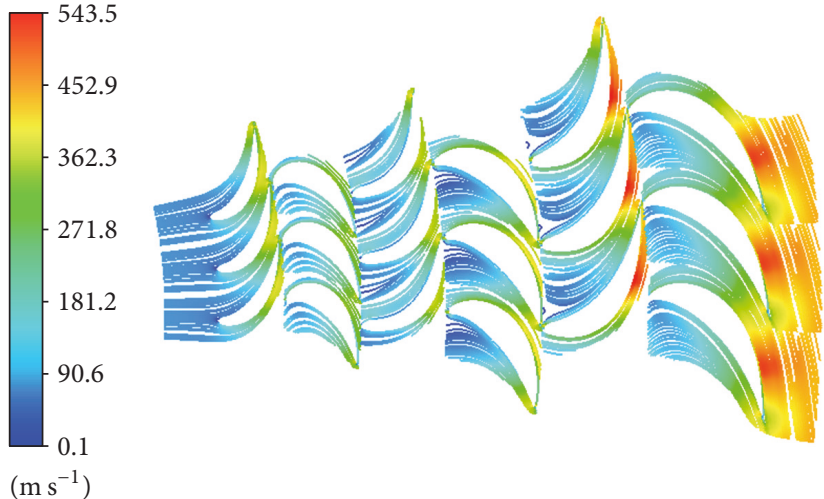

FIGURE 13: Streamline distribution.

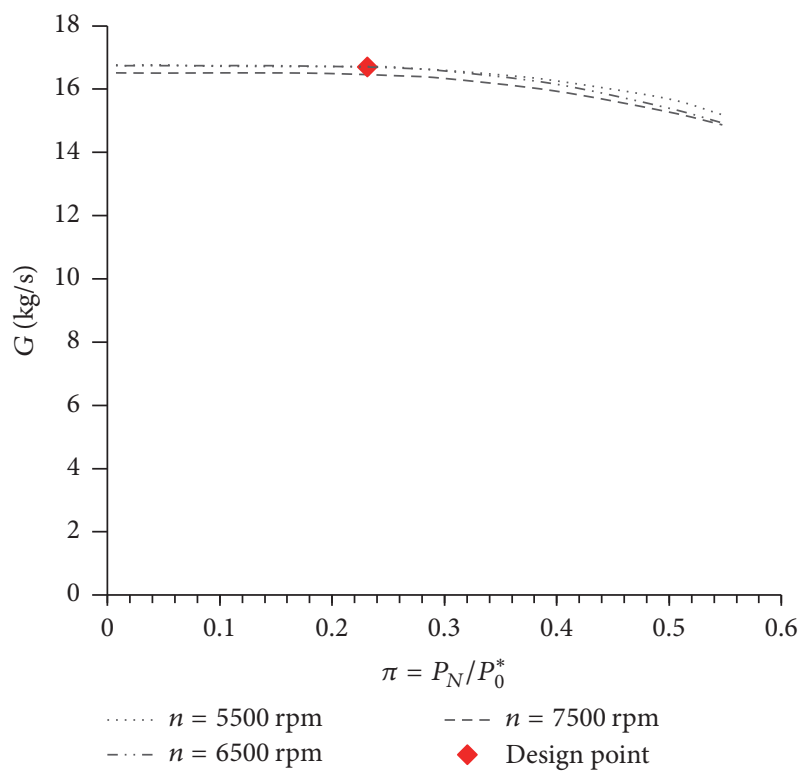

FIGURE 14: The variation of mass flow with pressure ratio at different speeds.

increases, the power curve drops faster when the pressure ratio increases.

Overall, it can be seen that the centrifugal turbine has a wide range and good off-design performance, from the

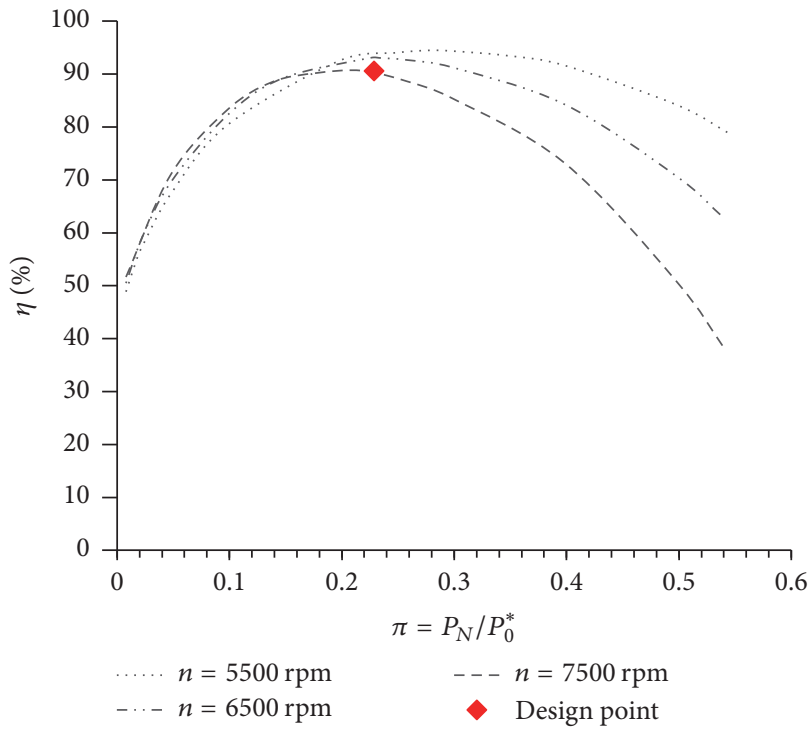

FIGURE 15: The variation of efficiency with pressure ratio at different speeds.

numerical simulation results of the three-stage centrifugal turbine and the analysis of the off-design conditions.

\section{Nomenclature}

T: $\quad$ Temperature, $\mathrm{K}$

$P$ : $\quad$ Pressure, $\mathrm{Pa}$

$h: \quad$ Enthalpy, $\mathrm{kJ} / \mathrm{kg}$

$s: \quad$ Entropy, $\mathrm{kJ} /(\mathrm{K} \cdot \mathrm{kg})$

$n: \quad$ Rotational speed, $r / \mathrm{min}$

G: $\quad$ Mass flow, $\mathrm{kg} / \mathrm{s}$

$b$ : Diameter ratio

$D$ : Diameter, $\mathrm{m}$

$R:$ Radius, $\mathrm{m}$

c: Absolute velocity, $\mathrm{m} / \mathrm{s}$

$w$ : Relative velocity, $\mathrm{m} / \mathrm{s}$

u: Circumferential velocity, $\mathrm{m} / \mathrm{s}$

$H$ : Height, $\mathrm{m}$

$N$ : Stage number

$W$ : Shaft power, $\mathrm{kW}$

Ma: Mach number. 


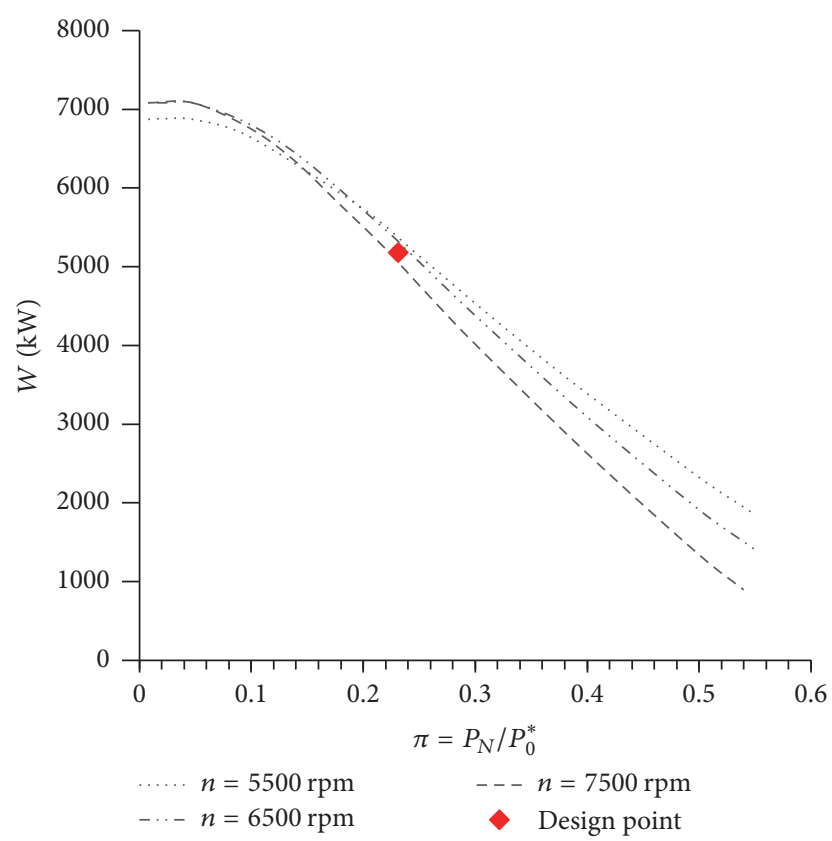

FIGURE 16: The variation of shaft power with pressure ratio at different speeds.

\section{Greek Letters}

$\rho:$ Density, $\mathrm{kg} / \mathrm{m}^{3}$

$\gamma$ : Radial symmetry cone angle, ${ }^{\circ}$

$\delta$ : Radial clearance between stator and rotor, $\mathrm{m}$

$\alpha$ : Absolute angle, ${ }^{\circ}$

$\beta$ : Relative angle, ${ }^{\circ}$

$\varphi$ : Stator flow coefficient

$\psi$ : Rotor flow coefficient

$\chi$ : Speed ratio

$\eta$ : Wheel efficiency

$\Omega$ : Reaction degree

$\pi$ : Pressure ratio.

\section{Subscripts}

0: First stage

in: Inlet

out: Outlet

$s: \quad$ Stator

$k$ : Stage number.

\section{Superscripts}

*: Stagnation condition.

\section{Conflicts of Interest}

The authors declare that they have no conflicts of interest.

\section{Acknowledgments}

This work was supported by National Natural science Foundation of China no. 51536006 and Shanghai Science and
Technology Committee with Grant no. 17060502300 and funded by Opening Project of Shanghai Key Laboratory of Multiphase Flow and Heat Transfer in Power Engineering no. 13DZ2260900.

\section{References}

[1] E. Coomes, R. Dodge, and D. Wilson, "Design of a high power-density ljüngstrom turbine using potassium as a working fluid," in Proceedings of the 21st Intersociety Energy Conversion Engineering Conference, vol. 3, San Diego, CA, USA, 1986.

[2] L. Jing and S. Peng, "Modification design and flowfield analysis of a centrifugal turbine stage with discrete nozzles," Journal of Aerospace Power, vol. 23, no. 6, pp. 1047-1053, 2008.

[3] L. Yin-Ge, T. Xin, and L. Xian-Qiao, "The thermal design and analysis of centrifugal turbine," Journal of Engineering Thermophysics, vol. 37, no. 10, pp. 2103-2010, 2016.

[4] T. Xin, L. Yin-Ge, L. Xian-Qiao et al., "Research on off-design characteristics of centrifugal turbine," Journal of Engineering Thermophysics, vol. 37, no. 6, pp. 1201-1208, 2016.

[5] T. Xin, L. Hui, S. Yan-Ping et al., "Design of the auxiliary components of the centrifugal turbine," Journal of Engineering Thermophysics, vol. 0253-231X, pp. 04-0000, 2017.

[6] M. Pini, G. Persico, E. Casati et al., "Preliminary design of a centrifugal turbine for organic rankine cycle applications," Engineering for Gas Turbines \& Power, vol. 135, no. 4, 2013.

[7] E. Casati, S. Vitale, M. Pini, G. Persico et al., "Centrifugal turbines for mini-organic rankine cycle power systems," Journal of Engineering for Gas Turbines \& Power, vol. 136, no. 136, Article ID 122607, 11 pages, 2014.

[8] G. Persico, M. Pini, V. Dossena, and P. Gaetani, "Aerodynamic design and analysis of centrifugal turbine cascades," in Proceedings of the ASME Turbo Expo: Turbine Technical Conference and Exposition, GT '13, vol. 6C, 12 pages, San Antonio, Texas, Tex, USA, 2013.

[9] G. Persico, M. Pini, V. Dossena et al., "Aerodynamics of centrifugal turbine cascades," Journal of Engineering for Gas Turbines \& Power, vol. 137, no. 11, Article ID 112602, 2015.

[10] M. Pini, A. Spinelli, G. Persico, and S. Rebay, "Consistent lookup table interpolation method for real-gas flow simulations," Computers \& Fluids, vol. 107, pp. 178-188, 2015.

[11] L. Yan-Sheng and L. Gui-Lin, Radial Turbine and Centrifugal Compressor, Machinery Industry Press, Bei Jing, China, 1987.

[12] W. Xin-Jun and L. Liang, Principle of Steam Turbine, XI'an Jiaotong University Press, Xi'an, Shaanxi, China, 2014.

[13] S. L. Dixon and C. A. Hall, Fluid Mechanics and Thermodynamics of Turbomachinery, Elsevier Inc Press, 2010. 


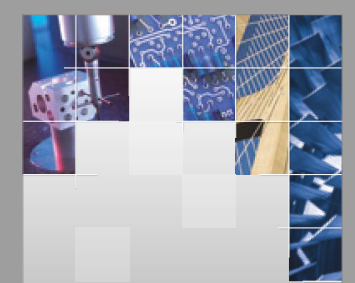

\section{Enfincering}
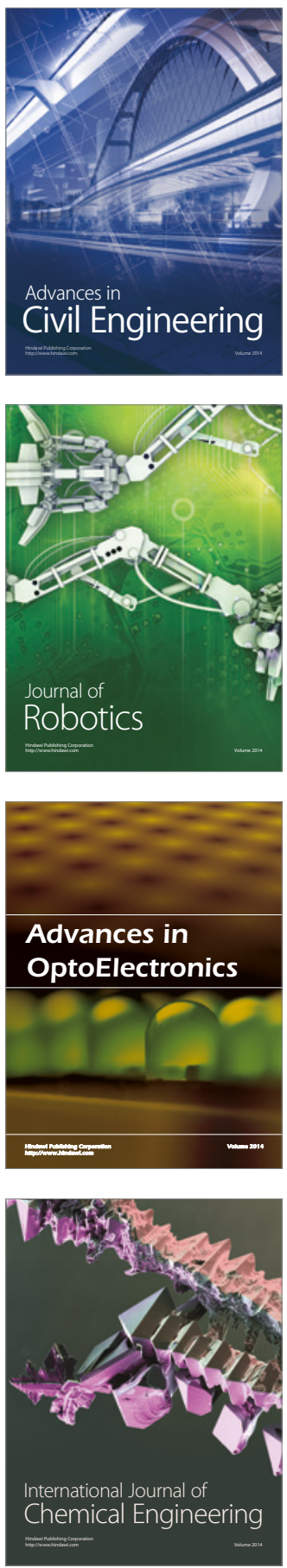

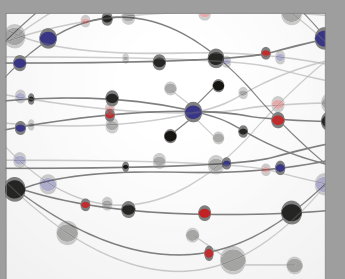

The Scientific World Journal

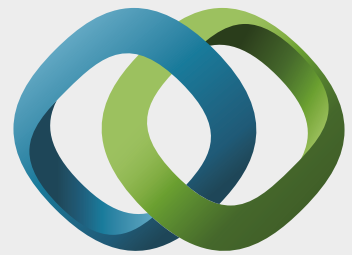

\section{Hindawi}

Submit your manuscripts at

https://www.hindawi.com
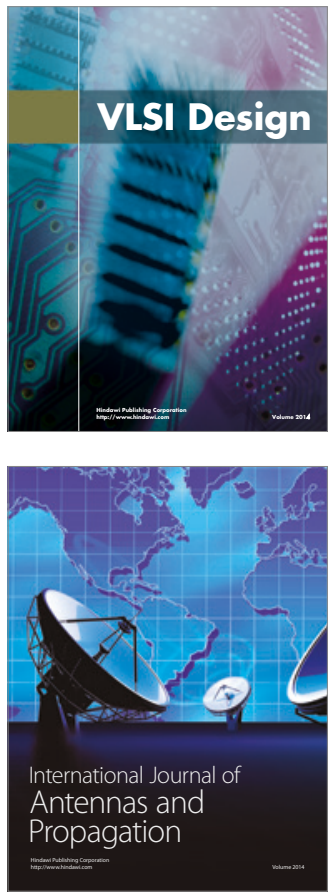

\section{Rotating}

Machinery
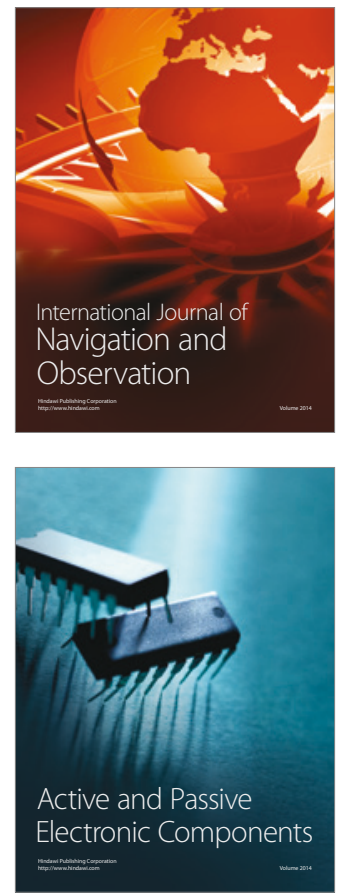
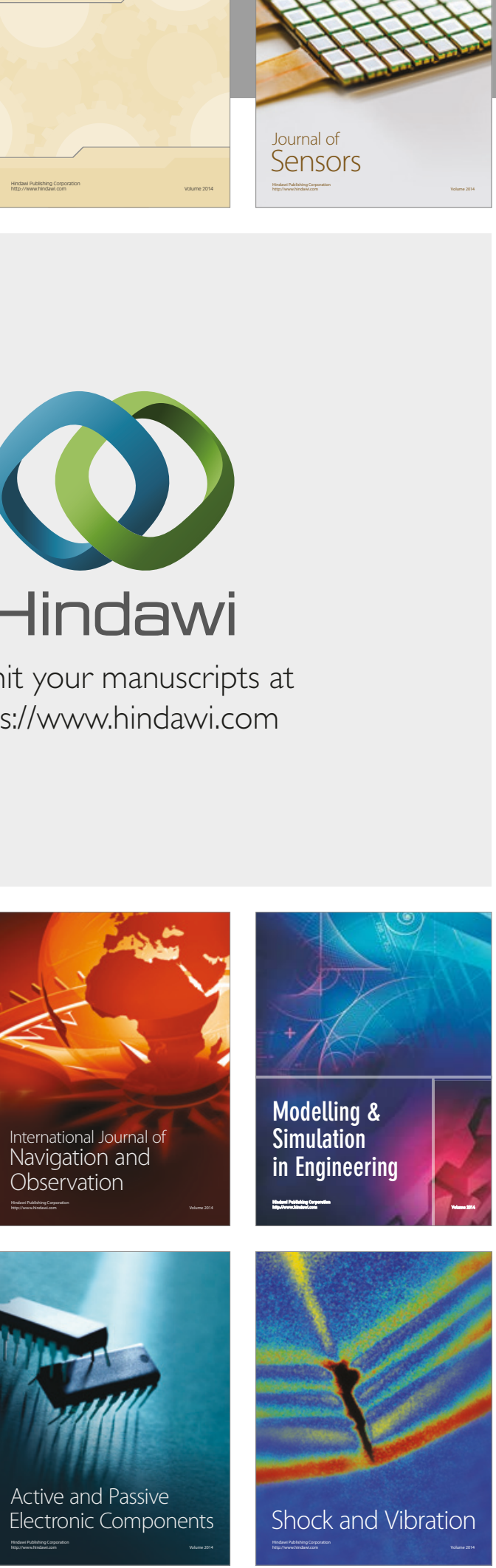
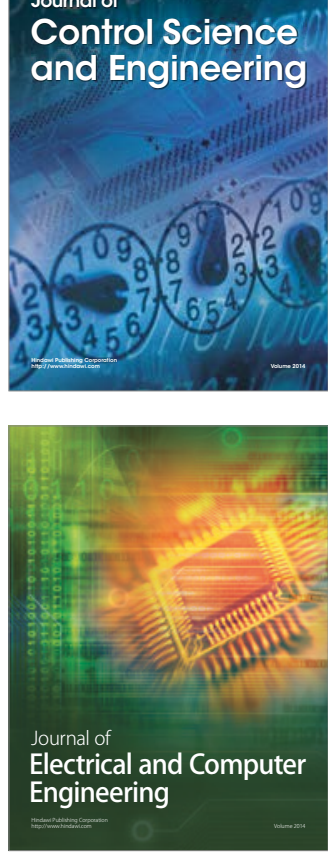

Distributed

Journal of

Control Science

and Engineering
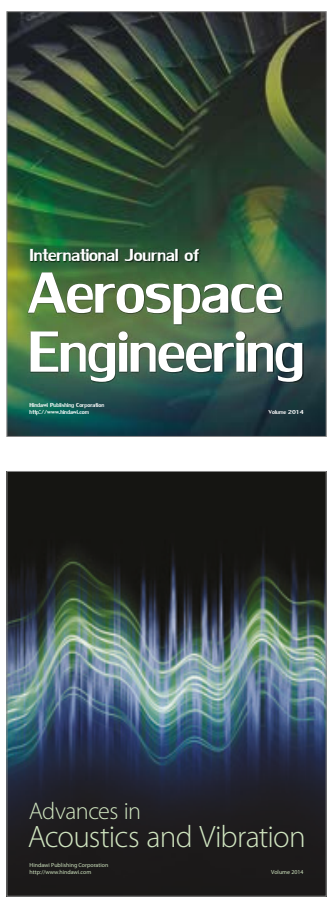

Sensor Networks 